\title{
Modelling Oil Pipelines Grid: Neuro-fuzzy Supervision System
}

\author{
Nagham H. Saeed \\ School of Computing and Engineering, University of West London, London, W5 5RF, UK. \\ E-mail: Saeenag@uwl.ac.uk \\ Maysam.F. Abbod \\ College of Engineering Design and Physical Science, Brunel University London, Uxbridge UB8 3PH, UK. \\ E-mail: Maysam.Abbod@brunel.ac.uk
}

Received: 13 April 2017; Accepted: 07 July 2017; Published: 08 October 2017

\begin{abstract}
One of the major challenges for researchers and governments across the world is reducing resourceswaste or loss. Resources loss can happen if there is not a capable control system that contributes to environmental change. The specific aim is to create user-friendly control and monitoring system to reduce the waste in resources. New Artificial intelligence techniques have been introduced to play an important part in developing such systems.

In oilfields, the oil is extracted then distributed via oil pipes until it reaches the end consumer. This operation will occur without a full and complete monitoring for the oil in the pipeline's journey to the provider. Although, the existing oilfield monitoring systems can communicate locally but they will not send information back to the main provider. That means the provider is not aware of the whole circumstances happened in the transportation process. That gives the provider no control on the process. For example, a sudden decision from the main provider to stop transporting to a specific destination or knowing where the leakage is and which pipe is leaking in the pipelines grid.

This paper, introduces for the first-time oilfield pipeline Neuro-fuzzy (NF) supervision system using Simscape simulation software package. This system can be the first step solution to keep real time communication between the main provider and the oil transportation process in the oilfields and enables the provider to have full supervision on the oil pipes grid. The simulation supervision system illustrates a clear real-time oilfield pipeline grid that gives the provider the ability to control and monitor pipeline grid and prioritise the recovering process. The two parameters selected for control and monitoring were volume and pressure. The results in this paper show full control for the NF supervision system on the transportation process.
\end{abstract}

Index Terms-Neuro-Fuzzy controllers, control and communication system, modelling, Simscape models.

\section{INTRODUCTION}

Oil becomes one of the essential basic commodities needed for daily activities ranging from driving cars to industrial activities. Oil for any country is the economic foundation and it has an extensive list of applications such as; transportation, road paving, military, defence, heating, plastics making, and electrical generation [1]. All these applications increase the oil market therefore there is a big demand for that product. Thus, oil becomes approximately an expensive product. Even recent drop in oil prices did not make it a cheap resource [2]. Therefore, controlling oil transportation is an important process and any damage to a pipe in the oil gird will come with a huge cost. British Petroleum (BP) oil Platform Explosion and oil Gusher in 2010 and 2015 Santa Barbra oil Spill in 2015 [3] are very good two examples for the damage this process can lead to environmentally and financially [4].

Renewable energy has been suggested to replace oil and other products [5] but until now oil is still the backbone of the major applications. Therefore, reliable and innovative solutions for oil and gas were introduced [6] in the industry which can help in safe detecting and monitoring. Many researches were introduced to improve the oil pipeline efficiency [8] and managing risks [9]. Pipeline can be under the threat of theft or damage especially in insecure countries, for example, the third world country such as Iraq [10].

In the view of the previous discussion, the security issue was raised to protect the oil production in the oilfields during transposition. The proposed monitoring and security systems can be another remarkable solution and can play a key role if it considered in the cases mentioned before. The system ensures the produced oil will reach its destination with minimum results of known loss (that includes product, equipment, labouring and time). The system minimizes the damage accrued to pipelines, stops the problem from developing, and reduces damage cost and time lost. It includes repairing and recovering time. 
The research aims are: Visual simulation for oil pipelines transmission grid, evaluate and analyse the parameters effecting oil pipelines transmission grid and create and evaluate AI monitoring and controlling system. The rest of the paper is organized as follows: section II dedicated for related work, section III showing clear diagram for the system and its concept, in section IV detailed explanation for the modelling procedure to create the physical and control subsystems in Simscape. Section $\mathrm{V}$ viewing the final Oil Pipelines Supervision System whereas section VI presents the settings and the simulation results for a normal condition while section VII contains a comprehensive discussion for two different case study to prove the effectiveness of the system. Finally, in section VIII the findings were summarized and future work was provided.

\section{RELATED WORK}

The oil traditional monitoring systems available today rarely have the two-way communications infrastructure [11] between the provider, oil pipes grid and the end consumer. In paper [12] an acknowledgement of one way of managing through utilizing satellite communications. The white paper explores the use of iDirect's advanced VSAT (very small aperture terminal) technology within the different segments of the energy industry. Beside the quality of the piping system should be ensured; for example, in paper [13] showing a development of a special testing machine to test the weak points in the pipe connections to ensure the quality of Natural Gas Piping Systems (NGPS) against any manufacturing defects

Artificial intelligence (AI) [13] was suggested as a problem solver for many problems because of its ability to estimate and predict [15]. For example, researchers [16] proposed AI to estimate reservoir parameters using the capabilities of AI optimized models; Neural Network Model (NN); Genetic Algorithm (GA), Particle Swarm Optimization (PSO), Ant Colony Optimization (ACO) to predict the nuclear magnetic resonance (NMR) log parameters in a carbonate reservoir rock of Iran. Whereas NF was implemented in [17] to monitor and evaluate oil condition of power transformer.

Whereas the most important contribution for the work in paper [18] is the use of NN to determine the leak location in the oil pipeline system while the work in [19] produce a survey of Computational Intelligence methods used to assess the safety of the oil and gas pipelines.

On another hand, Simscape modelling [20] based on the MATLAB programming language enables to investigate certain parameters and create new models. For example, Danilin et al. in [21] aimed to create a general approach to developing methods and algorithms designed for defining and providing memristor-based artificial neural network (ANNM) components operation accuracy in control and communication systems. They list factors that affect the operation accuracy of memristors used as the synapses in the ANNM. They had created Simscape models of memristor neurons and ANNM for investigating the influence of these factors on the ANNM accuracy. Whereas Kusagur et al. [22] used Simscape to introduce a novel design of an adaptive neuro fuzzy inference strategy (ANFIS) to control some parameters of the induction motor; such as speed, torque, flux, voltage and current.

\section{SYSTEM CONCEPT AND DESIGN}

The supervision simulation system presented in this paper is connecting the three parties together; the provider, oil pipes grid and the end consumer. Relying on the collected end consumer data and oil pipes grid's data the provider will start or stop supplying the oil through the pipe, besides monitoring the transportation process. Gauges installed on the oil pipes should provide sufficient information about the distribution oil pipes grid system to the provider. The gauges install on the oil pipes provide data in real time to the supervisor. It can capture certain features of the oil pipes, that can help in understanding the context in oilfield area and the provider can act accordingly. The supervisor analyses the information and then sends a decision (if required) to the oil pipes grid to apply. For example, in Figure 1 if the pressure gauge sends the actual pressure readings from the oil pipe. The supervisor will analyse the reading so if the pressure value starts to become different (increase or decrease) from the supervisor Neuro-Fuzzy (NF) models; then an action from the supervisor is needed. Also, temporary problems such as blockage or leakage in the oil pipe will demand an action from the supervisor.

To design Oil Pipelines Supervision System, the main stages for oil production/transportation should be identified and considered. Figure 1 represents a typical oilfield that consists of considerable pumps, pipelines and pumping rely stations. Pumps convey oil from production area to go through pipelines and pumping rely stations will support to pump the oil to reach its destination. Supervisor system should send the right commands to close or open the valves relaying on the information received from the pressure sensors on the oil pipelines. The proposed supervisor system should be able of controlling the entire process by the production valve and the relay valve as shown in Figure 1. 


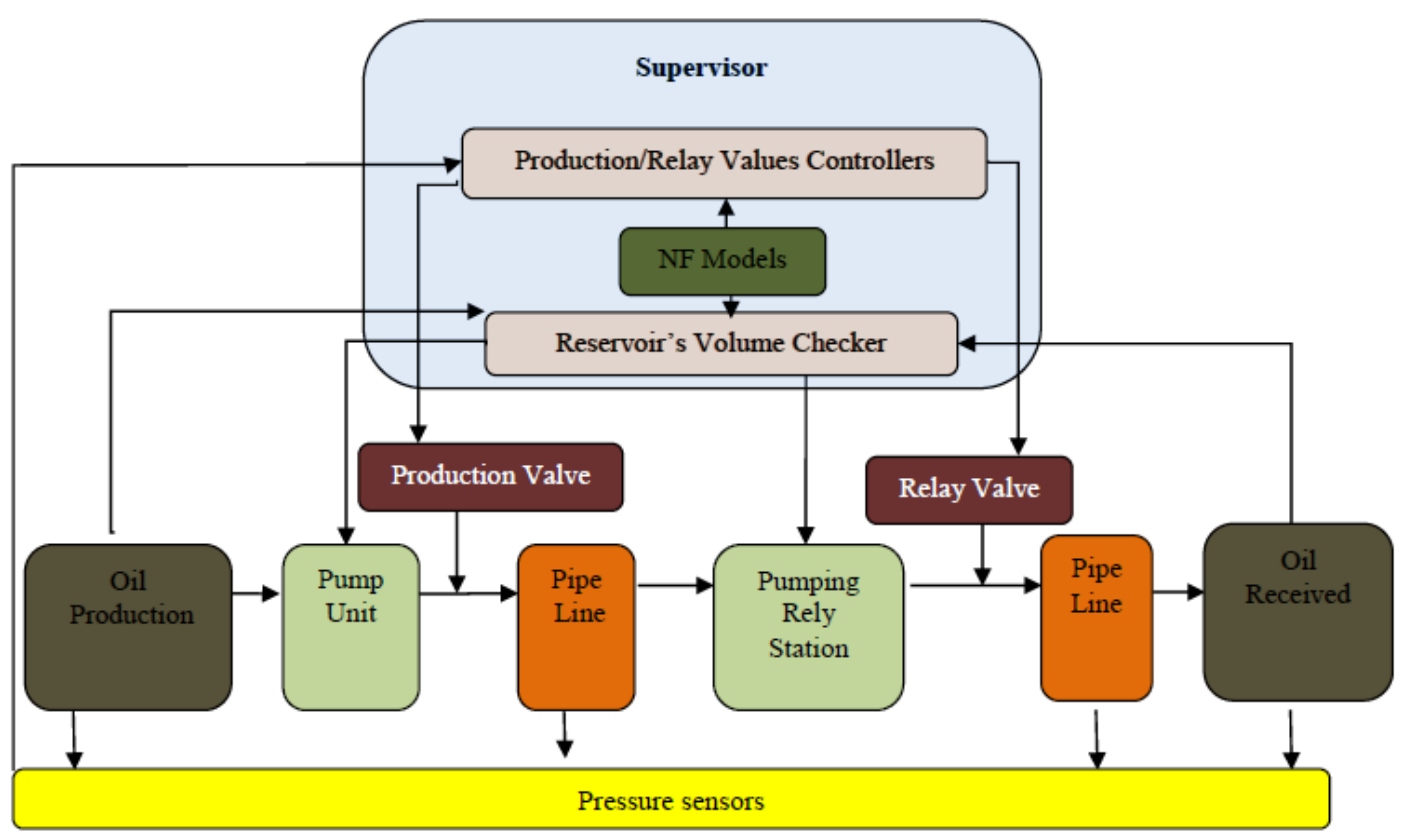

Fig.1. Oil Pipelines Supervision System Diagram

\section{SySTEM MODELLING}

As mentioned previously, the oil pipelines system can by represented in Simscape by means of many physical and control subsystems. To create such system in Simscape, each subsystem with its control signals should be built and tested individually. To create the final system in Figure 1 all the subsystems blocks will be merge together. The physical and control subsystems are:

\section{A. Physical Subsystems:}

As shown in Figure 1 diagram, the main physical subsystems in the supervision system are seven blocks: oil production (Reservoir Out), pump units, production valve, pipelines, pumping relay station, relay valve and oil received (Reservoir In). Brief definition for each component is presented below:

- Reservoir Out (Oil production) it is a tank full of oil.

- Pump unit(s) drains the oil from the source (Reservoir out) to pump it through the pipelines.

- Production valve controls the oil flows in the pipeline. The supervisor system controls this valve according to quantity in reservoir out.

- Pipelines transport the oil to the destination.

- Pumping relay station re-pumps the oil again to enable it to travel for longer distance and reach the destination.

- Relay valve controls the oil flows in the pipeline. The supervisor system controls this valve according to quantity in reservoir in.

- Reservoir In (Oil received) it is a tank filled with the oil sent from Reservoir out.

\section{B. Control subsystems}

As shown in Figure 1 diagram, the main control subsystem in Supervisor system. It controls the oil flow relaying on the pressure sensors measurements and the oil quantity in Reservoir out and Reservoir in. The Supervisor contains two main control subsystems: Reservoirs Volume Checker and Production/Relay Value Controllers, below a brief explanation for each subsystem:

1. Reservoirs Volume Checker: compares the reservoirs' (in and out) volumes and then sends on/off control signal to the first pump station. Oil volume will travel from the initial source Reservoir out through the pipeline and reached its destination in Reservoir In.

The main parameters formulate the volume checker are illustrated below:

$\mathrm{Vol}_{\text {out }}(\mathrm{set})$ and $\mathrm{Vol}_{\text {in }}$ (set) represent the production reservoir volume and the receiving reservoir volume respectively. The parameters represent the maximum volumes which reservoir should not be exceeded.

$\mathrm{Vol}_{\text {out }}$ (actual) and $\mathrm{Vol}_{\text {in }}$ (actual) represent the actual oil volume remain in reservoir out and the actual volume of oil received reservoir in respectively. That means $\mathrm{Vol}_{\text {in }}$ (actual) is how much the reservoir filled with oil.

$k_{\text {out }}=10$ and $k_{\text {in }}=100$ are the gain parameters to amplify the results. The volume checker controls the pump operation. It will send signals to switch the motor on or off according to the equation below:

$$
\begin{gathered}
P u m p_{\text {signal }}=K_{\text {in }}\left(\operatorname{Vol}_{\text {in }}(\text { set })-V_{\text {ol }}(\text { actual })\right) * \\
k_{\text {out }}\left(V_{\text {out }}(\text { actual })-\operatorname{Vol}_{\text {out }}(\text { set })\right)
\end{gathered}
$$


Equation (1) is the production of the difference between the actual and the set volumes for Reservoir in and Reservoir out

2. Production/Relay Value Controllers: They control the oil flowing in the pipelines by sending control signals to open or close the valves. The valves according to the control signals will allow the oil to flow or block. Signal 1 is controlling the production valve while signal 2 is controlling the relay valve.

The control valve signal will be sending on or off signal relaying on the pressure equation, below is the production valve equation:

$$
\text { Valve Direction }=\text { Pressure }_{\text {before }}-\text { Pressure }_{\text {after }}
$$

The production valve sustains the oil flowing in the pipelines if and only if the result of the above equation is not zero. Regularly, the oil pressure is expected to drop through the oil's long journey in the pipes. Therefore, the valves will be open if the oil pressure before it entered a certain pipeline is more than when it left that pipeline. And vice versa; that means the valves will be closed if the oil pressure before it entered a certain pipeline is less than when it left that pipeline.

That means when destination (Reservoir In) is nearly full the supervisor should send a signal to close the production valves.

The Supervisor adopts the same pressure difference principle in equation (2) to control the oil flowing after the relay pumping station.

\section{IMPLEMENTATION}

The final Oil Pipelines Supervision System was simulated in Matlab/Simscape as shown in Figure 2. The Figure illustrates the Supervisor System controls the oil transportation process. The system controls the oil transportation relaying on the measured pressures as well as the reservoirs volumes. Most of the components used in this simulation were from the hydraulic library in Simulink/Simscape.

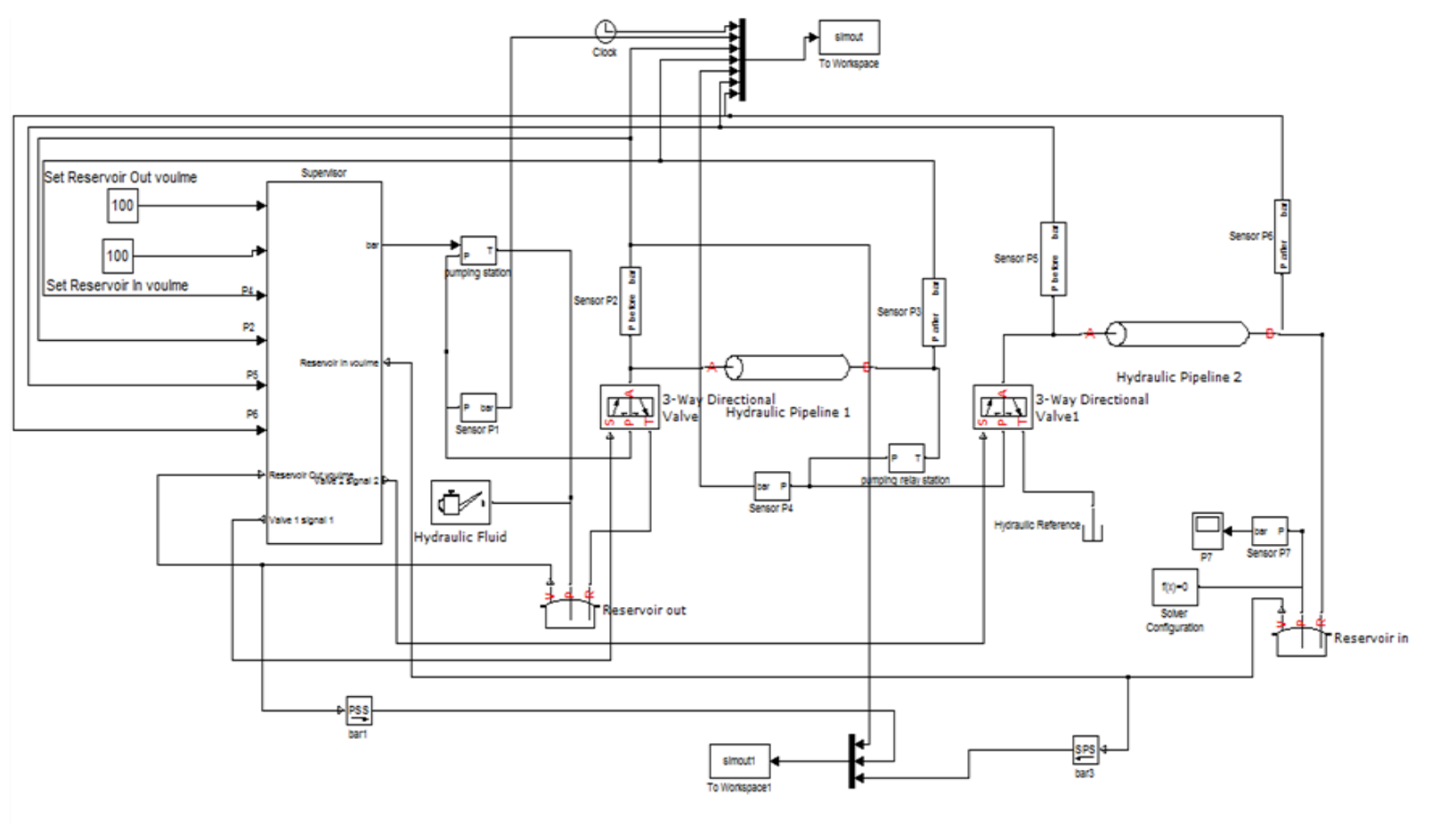

Fig.2. Oil Pipelines Supervision System in Simscape

The hydraulic components were all set to small values to produce high pressure. In this research, the values for the components were changed to meet the requirement for transporting oil for a long distance and brief time. To know the pressure data, six pressure sensors were planted on the oil pipes as shown in Figure 2. Each sensor measures the oil pressure in a certain position in the transportation process, the sensors positions are listed below:

P1: after oil pumps, out the pumping station
P2: before oil travels through the first pipeline. P3: after oil comes out from the first pipeline. P4: after oil pumps, out the pumping relay station. P5: before oil passes through the second pipeline. P6: after oil comes out from the second pipeline

It is also worth mentioning that the pressure sensors were simulated and practical results were not covered in this paper. In practical research, piezoelectric sensors can be recommended as pressure sensors to save energy [23].

Many parameters were adjusted to create the final 
system such as: the length of the pipeline, the diameter of the pipeline, the motor speed in the relay and the pump station. In this research, these parameters allowed the supervision system to control and communicate throughout the transportation process.

\section{IMPLEMENTATION}

The final Oil Pipelines Supervision System was simulated in Matlab/Simscape as shown in Figure 2. The Figure illustrates the Supervisor System controls the oil transportation process. The system controls the oil transportation relaying on the measured pressures as well as the reservoirs volumes. Most of the components used in this simulation were from the hydraulic library in Simulink/Simscape. The hydraulic components were all set to small values to produce high pressure. In this research, the values for the components were changed to meet the requirement for transporting oil for a long distance and brief time. To know the pressure data, six pressure sensors were planted on the oil pipes as shown in Figure 2. Each sensor measures the oil pressure in a certain position in the transportation process, the sensors positions are listed below:

P1: after oil pumps out the pumping station

P2: before oil travels through the first pipeline.

P3: after oil comes out from the first pipeline.

P4: after oil pumps out the pumping relay station.

P5: before oil passes through the second pipeline.

P6: after oil comes out from the second pipeline

It is also worth mentioning that the pressure sensors were simulated and practical results were not covered in this paper. In practical research, piezoelectric sensors can be recommended as pressure sensors to save energy [23].

Many parameters were adjusted to create the final system such as: the length of the pipeline, the diameter of the pipeline, the motor speed in the relay and the pump station. In this research, these parameters allowed the supervision system to control and communicate throughout the transportation process.

\section{NORMAL CONDITION}

Supervision system was tested by simulating the first benchmark scenario; the aim for the first simulation is to estimate the time required to transport a specific amount of oil in normal conditions. Additionally, it will record the pressure for the six gauges through the time. Table 1 shows the system setting parameter [23] in Simscape simulation for a normal condition. The reservoir's parameters were adjusted as clarified below:

Reservoir out: The volume required was set to $100 \mathrm{~m}^{3}$ and its initial volume $200 \mathrm{~m}^{3}$. The initial volume is double the required volume since Simscape simulation will not run if the initial volume for Reservoir out= required volume for Reservoir out.
Reservoir in: The volume required was set to $100 \mathrm{~m}^{3}$ and its initial volume $0.02 \mathrm{~m}^{3}$.

Table 1. Normal condition simulation parameters

\begin{tabular}{|c|c|}
\hline \multicolumn{2}{|r|}{ Simulation parameters } \\
\hline \multirow{5}{*}{ Reservoir out } & $\mathrm{Vol}_{\text {out }}$ (set) $100 \mathrm{~m}^{3}$ \\
\hline & $\mathrm{Vol}_{\text {out }}($ initial $)=200 \mathrm{~m}^{3}$ \\
\hline & Pressurization level $=0$ \\
\hline & Return line diameter $=0.02 \mathrm{~m}$ \\
\hline & Pressure loss coefficient in return line $=1$ \\
\hline \multirow{5}{*}{ Reservoir in } & $\operatorname{Vol}_{\text {in }}(\mathrm{set})=100 \mathrm{~m}^{3}$ \\
\hline & $\mathrm{Vol}_{\text {in }}($ initial $)=0.02 \mathrm{~m}^{3}$ \\
\hline & Pressurization level $=0$ \\
\hline & Return line diameter $=0.02 \mathrm{~m}$ \\
\hline & Pressure loss coefficient in return line $=1$ \\
\hline \multirow{6}{*}{ Pump station } & Pump displacement $=5 \mathrm{E}-6 \mathrm{~m}^{3} / \mathrm{rad}$ \\
\hline & Volumetric efficiency $=0.92$ \\
\hline & Total efficiency $=0.8$ \\
\hline & Nominal pressure $=10 \mathrm{MPa}$ \\
\hline & Nominal angular velocity $=188 \mathrm{rad} / \mathrm{sec}$ \\
\hline & Nominal kinematics viscosity $=18 \mathrm{cSt}$ \\
\hline \multirow{10}{*}{ pipeline } & Pipe cross section type $=$ circular \\
\hline & Pipe internal diameter $=0.1 \mathrm{~m}$ \\
\hline & Geometrical shape factor $=64$ \\
\hline & Length $=20 \mathrm{~km}$ \\
\hline & Aggregate equivalent of local resistance $=1 \mathrm{~m}$ \\
\hline & Internal surface roughness height $=1.5 \mathrm{E}-05 \mathrm{~m}$ \\
\hline & Laminar flow upper margin $=2000$ \\
\hline & Turbulent flow lower margin $=4000$ \\
\hline & Pipe wall type $=$ Rigid \\
\hline & Specific heat ratio $=1.4$ \\
\hline \multirow{8}{*}{$\begin{array}{l}\text { Hydraulic } \\
\text { valves }\end{array}$} & $\begin{array}{c}\text { Model parameterization = By maximum area } \\
\text { and opening }\end{array}$ \\
\hline & Valve passage maximum area $=0.05 \mathrm{~m}^{2}$ \\
\hline & Valve maximum opening $=0.5 \mathrm{~m}$ \\
\hline & Flow discharge coefficient $=0.7$ \\
\hline & Orifice P-A initial opening $=0 \mathrm{~m}$ \\
\hline & Orifice A-T initial opening $=0 \mathrm{~m}$ \\
\hline & Critical Reynolds number $=12$ \\
\hline & Leakage area $=1 \mathrm{E}-12 \mathrm{~m}^{2}$ \\
\hline $\begin{array}{c}\text { Simulation } \\
\text { time }\end{array}$ & $8226 \mathrm{sec}$ \\
\hline
\end{tabular}

The system contains two pipelines the length for each one is $20 \mathrm{~km}$ and their internal diameter was $0.1 \mathrm{~m}$. The parameters for the two hydraulic valves [24], [25] were adjusted also. The $1^{\text {st }}$ and $2^{\text {nd }}$ valve passage maximum area is $0.05 \mathrm{~m}^{2}$ and maximum opening is $0.5 \mathrm{~m}$. The oil in the first pump station and the second relay pump station was pumped with pump displacement set to $5 \mathrm{E}-6 \mathrm{~m}^{3} / \mathrm{rad}$. Simulation time was set arbitrarily to $8226 \mathrm{sec}$.

The simulation for the system in Figure 2 ran successfully until $\mathrm{t}=8226 \mathrm{sec}$, that simulation time was enough to transport specific amount of oil $\left(100 \mathrm{~m}^{3}\right)$. That is almost half the amount of the oil in Reservoir out was transported to Reservoir in. The simulation helps to be acquainted with the time required to transport the same amount of oil in normal cases as shown in Figure 3. The simulation also provides the pressure measurements on the pipes through the entire process. 
The volume and pressure sensors were allocated in various positions to have a good understanding for the entire process. The supervision system checked regularly the data sent from sensors and accordingly to their values commands that meet the conditions were sent to the pump and the valves. Table 2 illustrates the readings for volume sensors in the beginning $(\mathrm{t}=0 \mathrm{sec})$ and the end of the simulation $(\mathrm{t}=8226 \mathrm{sec})$, the reading was by the two sensors utilized in the transportation process.

Simulation readings for pressure sensors $\mathrm{P} 1$ and $\mathrm{P} 2$ in Figure 5 were very similar. As mentioned before, P1 was allocated before valve 1 and $\mathrm{P} 2$ was allocated after valve 1 therefore there was no difference in the pressure reading between the two sensors. The same principle applied for the two pressure sensors P4 and P5 for valve 2. Therefore, because of the similarity P1 and P4 data were excluded. Figure 4 illustrates the pressure sensors readings for $\mathrm{P} 2, \mathrm{P} 3, \mathrm{P} 5$ and $\mathrm{P} 6$ through the time. The pressure simulation results in the Figure were as predicted, where all the pressure sensors' reading started with zero at $\mathrm{t}=0 \mathrm{sec}$ as there was no oil passing through the pipes then the pressure gradually started to build up due to the pumped oil; the highest reading value was for $\mathrm{P} 2$ as it is the nearest to the reservoir out. The other sensors readings were less as the pressure started to drop through the oil journey, which was expected. P6 shows the pressure sensed before the last destination (reservoir in). The pressure was low most of the time as this sensor is to check the pressure for the oil before reservoir in and there is no need for a pumping station to increase the oil pressure. After reaching the required amount of oil the system closed the pump and the valves. The effect of this closure is shown clearly in the Figure as all the sensors readings graphs shows that the pressure started to drop down rapidly until they reached zero. That represent no oil was passing in the pipes.

Table 2. Volume sensors readings

\begin{tabular}{|c|c|c|}
\hline Volume sensor & Start value ${\left(\mathbf{m}^{3}\right)}$ & End value $\left.\mathbf{( m}^{3}\right)$ \\
\hline Vol $_{\text {out }}$ (actual) & 200 & 100.27 \\
\hline Vol $_{\text {in }}$ (actual) & 0.02 & 99.367 \\
\hline
\end{tabular}

Figure 3 illustrates the volume sensors readings through the time. As shown in the Figure $\mathrm{Vol}_{\text {in }}$ (actual) graph was increased through the time to the required value, then it will set on $100 \mathrm{~m}^{3}$ while $\mathrm{Vol}_{\text {out }}$ (actual) was reduced by $100 \mathrm{~m}^{3}$ through the time. That proofs the amount of oil sent has been received.

In general, the normal condition simulation results are very helpful since Nuero-Fuzzy (NF) Models will be based on them. NF models were created from the data achieved in the normal condition simulations. The supervisor system used NF models as a benchmark to compare them with any other scenarios. 3D models were created for the supervision system prediction, which helped in the decision-making. Two models were for pressure sensors $\mathrm{P} 2$ and P3against $\mathrm{V}_{\text {out }}$ and $\mathrm{V}_{\text {in }}$. These models will contribute in the control of valve 1 and valve 2, therefore P5 and P6 models were excluded, as they were not beneficial.

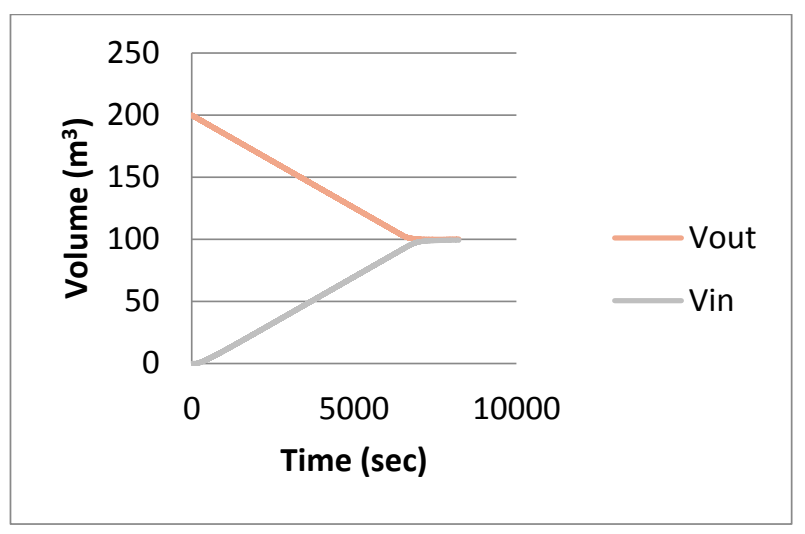

Fig.3. Volume sensors readings for normal condition

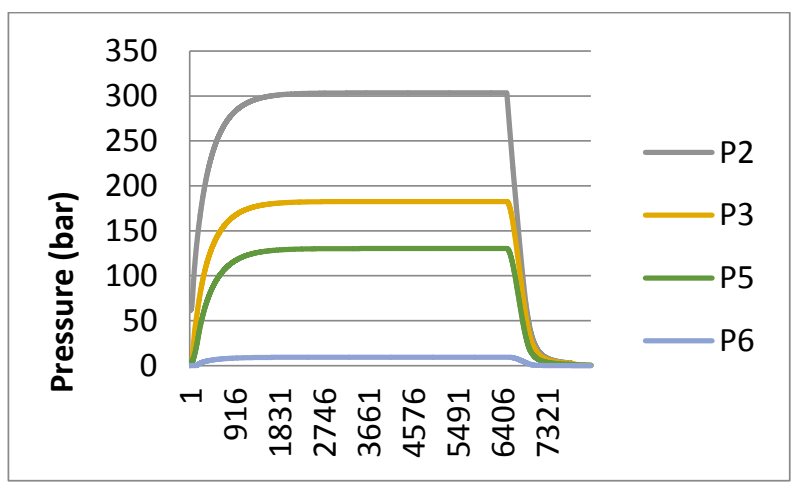

Fig.4. Pressure sensors for normal condition

\section{DISCUSSION}

In the previous implementation section, the measurements presented for the pressure and the volume were for normal situation where the system is operation without any problems. In this section, three different scenarios will be considered to demonstrate the control for the supervision system. The first scenario shows the condition where Reservoir in is requesting less than the normal amount of oil, the second scenario considers a problem in a pipeline without NF models control and the third and final scenario considers a problem in a pipeline with NF models control. More details about each scenario are presented below:

\section{Scenario A - Reservoir in request less than the normal} amount

In this simulation case, Reservoir in is requesting half of the amount demanded in the normal condition. This case shows the adaptation ability of the proposed system to the required value. Reservoir in required volume was set to $50 \mathrm{~m}^{3}$ instead of $100 \mathrm{~m}^{3}$ as shown in Table 3 . The rest of the parameters were set with the same values in Table 1. Figure 5 shows oil volume in Reservoir in $\left(V_{\text {in }}\right)$ and Reservoir out $\left(\mathrm{V}_{\text {out }}\right)$ through the time, from $\mathrm{t}=0 \mathrm{sec}$ to $3484 \mathrm{sec} \mathrm{V}_{\text {out }}$ was sending the required oil volume whereas at $\mathrm{t}=3871 \mathrm{sec} \mathrm{V}_{\text {in }}$ received the required oil volume. 
Table 3. Scenario A simulation parameters

\begin{tabular}{|c|c|c|}
\hline Reservoir & $\begin{array}{c}\text { Volume } \\
\text { Set }(\mathbf{m} 3)\end{array}$ & initial volume $(\mathbf{m 3})$ \\
\hline Reservoir Out & $\operatorname{Vol}_{\text {out }}(\mathrm{set})=100$ & $\mathrm{Vol}_{\text {ou }}($ initial $)=200$ \\
\hline Reservoir in & $\operatorname{Vol}_{\text {in }}(\mathrm{set})=50$ & $\mathrm{Vol}_{\text {in }}($ initial $)=0.02$ \\
\hline
\end{tabular}

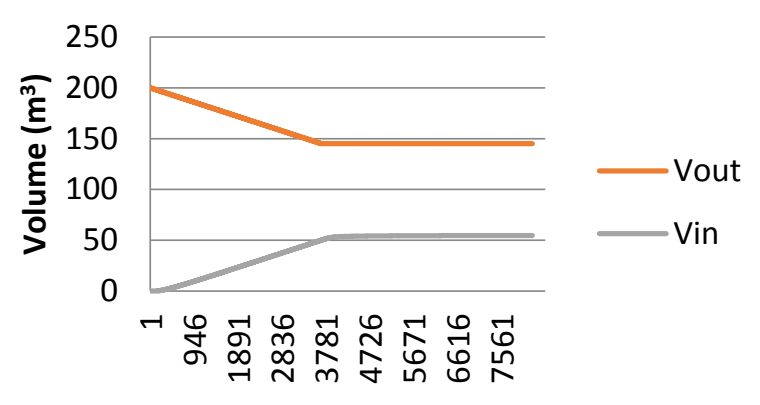

Fig.5. Volume sensors measurements for scenario A

Figure 6 shows the sensors readings for pressure through the time that increase in the beginning of the simulation. Then the readings will have constant values until the required volume achieved where a rapid decrease will acquire in all the sensor readings until they will set to zero.

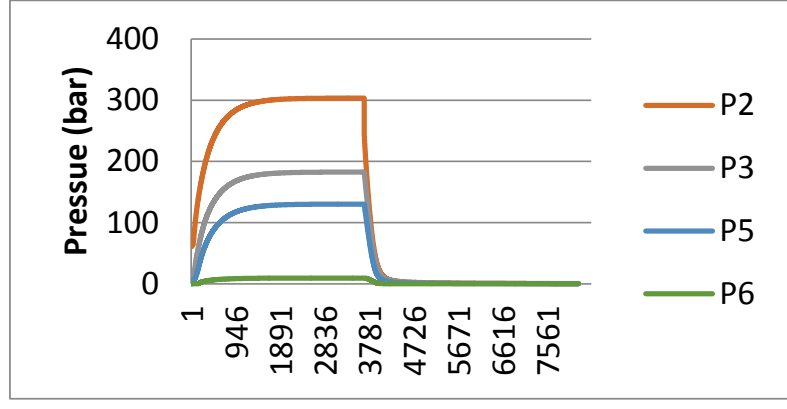

Fig.6. Pressure sensors measurements for scenario A

Scenario B-Leakage problem in pipelines system without NF model supervision

To create this simulation scenario, an intruder reservoir was added to the system design to represent a leak after pump relay station. The intruder reservoir collects the leaked oil from a certain pipe (first leaked pipeline). Figure 7 shows the leak is happening before pipeline 1 . The simulation parameters are like scenario A and Table 3.

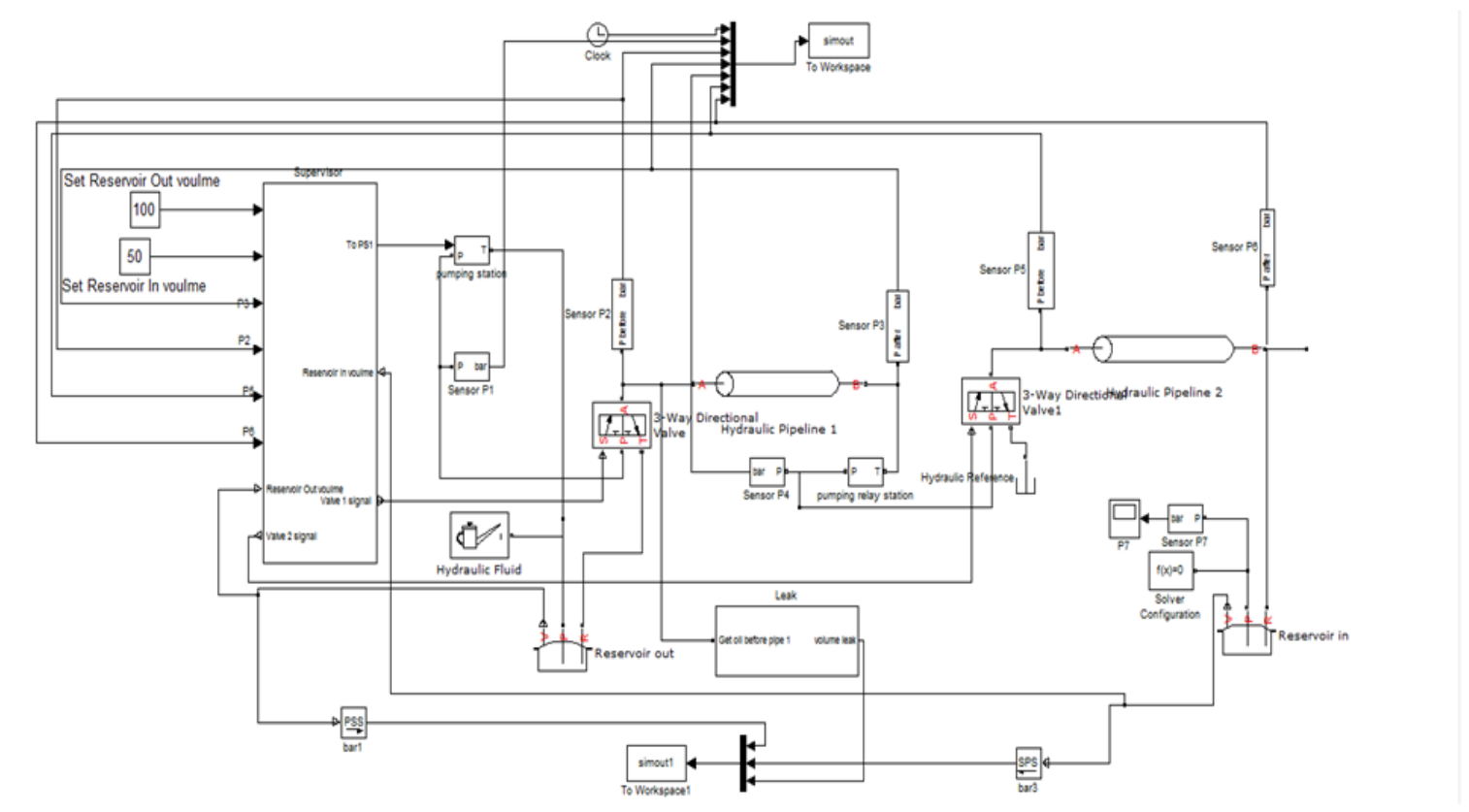

Fig.7. Oil Pipelines Supervision System for scenario B without NF models' supervision

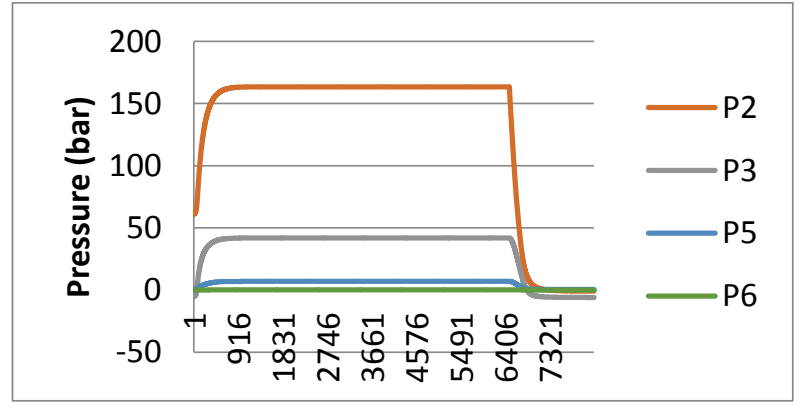

Fig.8. Pressure sensors readings in leak condition
To create this simulation scenario, an intruder reservoir was added to the system design to represent a leak after pump relay station. The intruder reservoir collects the leaked oil from a certain pipe (first leaked pipeline). Figure 7 shows the leak is happening before pipeline 1 . The simulation parameters are like scenario A and Table 3.

Comparing Figure 8 with Figure 6, it is clear the time to send the required oil volume was longer in Figure 8 than Figure 6, it was about double the time required in the normal case. The pressure sensors show measurements 
for a longer period than the period in Figure 3. It is noticeable that in Figure 8 the pressure reading drops in all the sensors because of the leak in pipe 1 . The pressure sensors show lower measurement values than the values in the normal condition (Figure 3). P3 readings include negative readings in the beginning and the end because of the leak before pipe 1 . The negative values represent the situation where there was no oil to pump and air was pumped instead.

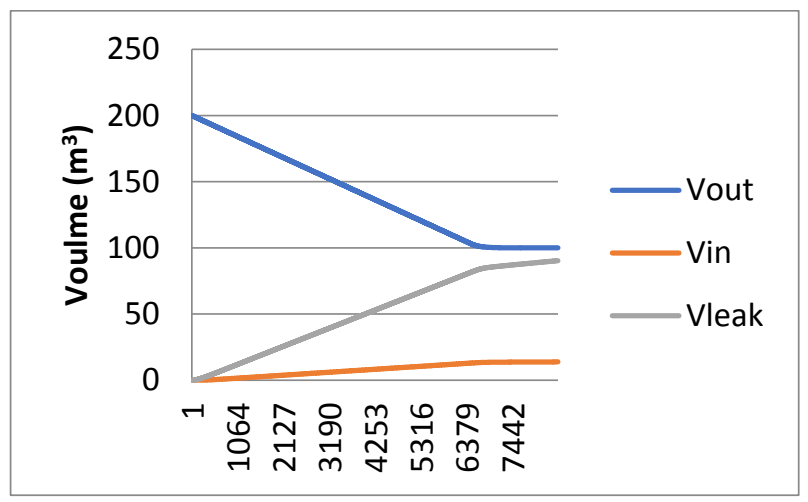

Fig.9. Volume sensors reading in leak condition
The pump on the Reservoir out $\left(\mathrm{V}_{\text {out }}\right)$ continued to pump oil until it reached the setting value $100 \mathrm{~m}^{3}$ which is double the volume required. Then the supervisor sent the control off signals to switch the pump and the valves off. Most of the oil pumped was in the intruder reservoir $\left(\mathrm{V}_{\text {leak }}\right)$ as shown in Figure 9. At the end of the simulation, $\mathrm{V}_{\text {leak }}$ reached about $89.5 \mathrm{~m}^{3}$ where $\mathrm{V}_{\text {in }}$ was $18.31 \mathrm{~m}^{3}$.

Scenario C - Leakage problem in pipelines system with NF model supervision

Neuro-fuzzy synergisms are for modelling and control. The essential part of neuro-fuzzy synergisms comes from a common framework called adaptive networks, which unifies both neural networks and fuzzy models. The fuzzy model under the framework of adaptive networks was called Adaptive-Network-based Fuzzy Inference System (ANFIS), which possess certain advantages over neural networks [26][27][28].

As illustrated in Figure 10, the supervision system compares the sensors data with NF model, if there is no difference between the two readings; for the volume and the pressure, the pipelines will keep transporting the oil but if there is a difference, the system will send control signals to close the pump and the valves.
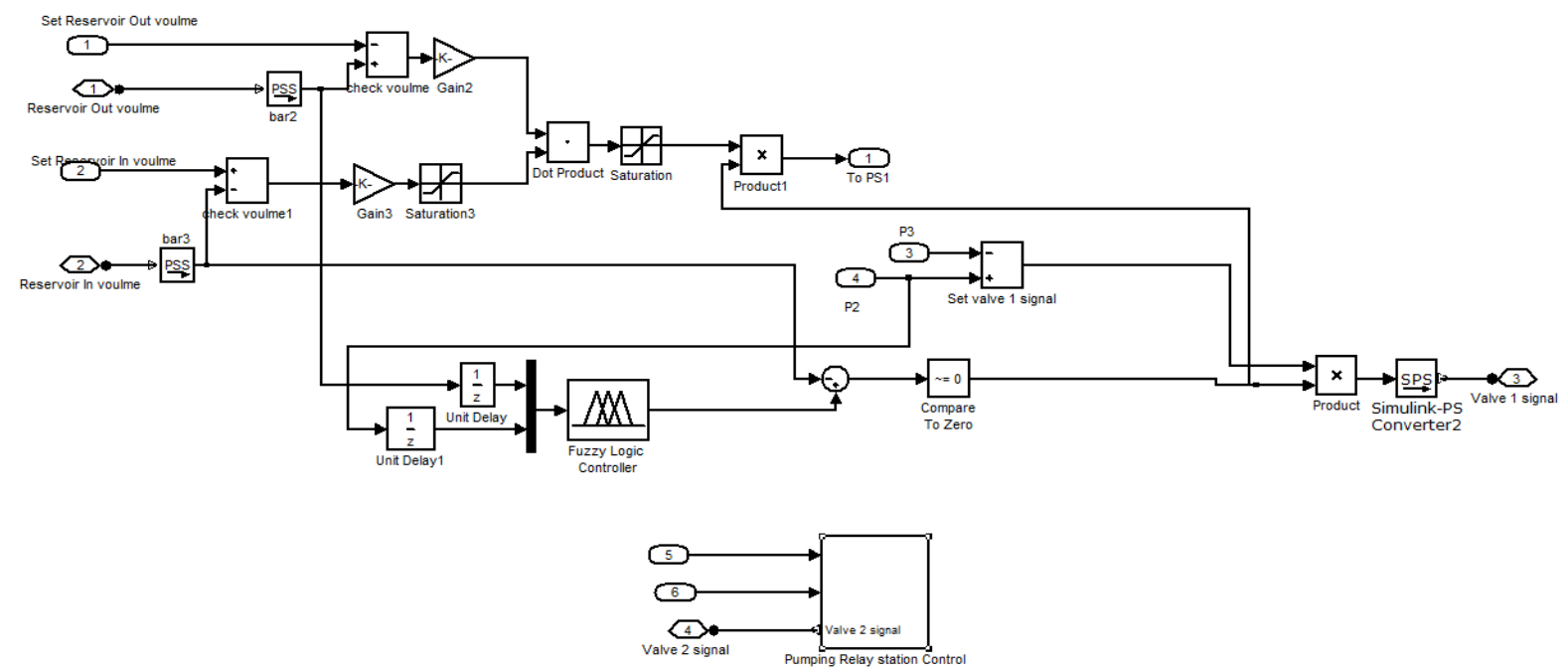

Fig.10. Supervision system with NF model

Data from P2 (sensor allocated before valve 1) $V_{\text {in }}$, and out sensors are important to control the process. Then the data were sampled after $200 \mathrm{sec}$. Consequently, Neurofuzzy (NF) model was created form the sensors readings for the oil translation in the normal condition; NF model. The 3D Model represents the pressure measurements on that certain point against the volumes $\left(\mathrm{V}_{\text {out }}\right.$ and $\left.\mathrm{V}_{\text {in }}\right)$. Therefore, the model was embedded in the supervisor system. The model helps in decision-making, which means sending open/close command signals to the valves and the pump.

Number of membership function (MF) is 2 by 2 where MF type is Gaussian [29]. Many other membership functions were considered such as Generalized bellshaped MF, Triangular-shaped MF, Difference between two sigmoidal MF but the best MF which represents the data taken was 2 by 2 Gaussian MF. ANFIS training completed at epoch 2 with an error 0.115643 . The model rules are:

If (Vout is High) and (Pressure sensor 2 is Low) then (Vin is Low)

If (Vout is High) and (Pressure sensor 2 is High) then (Vin is Very Low)

If (Vout is Low) and (Pressure sensor 2 is Low) then (Vin is Medium)

If (Vout is Low) and (Pressure sensor 2 is High) then (Vin is High) 


\section{CONCLUSIONS}

An intelligent oil pipeline supervision system has been proposed in this paper to monitor and control the oil transportation process. The system relies on intelligent communication.

The embedded NF model in the supervision system represents the pressure in certain point against volume in and volume out. Figure 11 presents 3D model for the simulation $\mathrm{V}_{\text {in }}$ required was $50 \mathrm{~m}^{3}$. The model represents $\mathrm{P} 2$ pressure, $\mathrm{V}_{\text {out }}$ and $\mathrm{V}_{\text {in }}$ for sensor readings through the time. The model is used for comparison and prediction; it counts as a reference model. If there is a difference between the reference reading and the actual reading that exceeds the allowed value, then there should be an action to stop pump 1operation and close the valves.

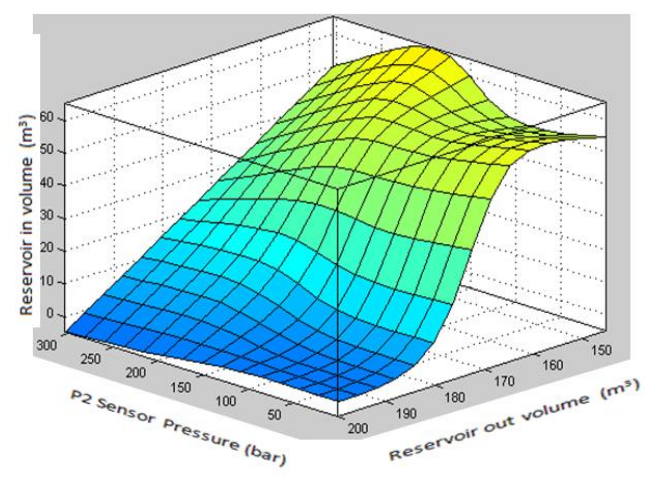

Fig.11. NF Model Surface

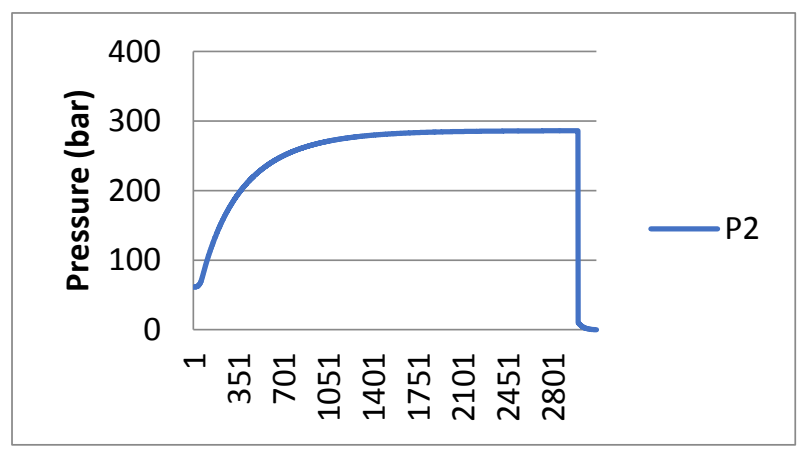

Fig.12. P2 sensors readings for scenario C

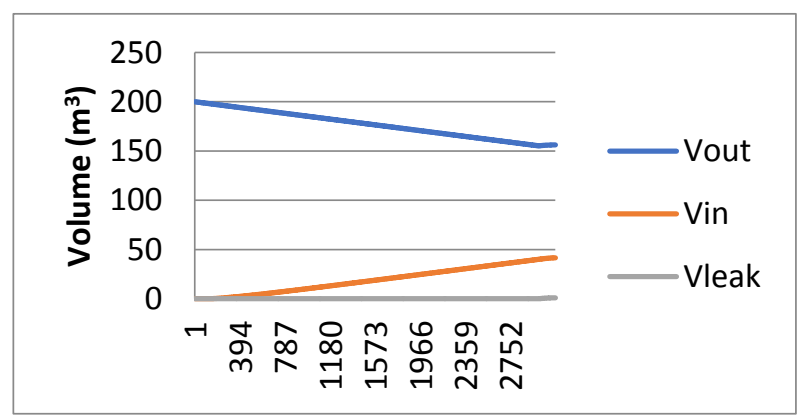

Fig.13. Volume sensors readings for scenario C

Scenario C simulation ran successfully with a leak starting from $\mathrm{t}=3000 \mathrm{sec}$. The leak unit is shown in Figure 7 before oil pipeline 1 and simulation parameters were the same in Table 3. NF model was embedded to the supervision system to participate in controlling the process. Figure 12 shows the reading for the pressure sensor P2 and Figure 13 volumes for scenario C simulation. It is clearly shown that the pressure readings are different from the pressure reading in Figure 8 and it has response to the supervisor command. After $t=3000$ sec, the pressure sensors reading reflect the fact that the valve was close and approximately small pressure readings were measured; they were approximately near to zero. That means there is no oil passing in the pipes. Also, Figure 13 shows the $\mathrm{V}_{\text {leak }}$ near zero, which is a significant difference from Figure 9.

The target to reduce the leakage loss has been achieved in this research with the support of NF supervision system. The oil transportation will be stopped if there is any leak in the pipe at any time. That will allow the repair to take place as soon as possible.

system to prevent oil losses. NF models had the ability to predict the time required to transport a certain amount of oil. A benchmark scenario was simulated to represent normal conditions and then three case studies were created to test the system: Scenario A-Reservoir in request less than the normal amount, Scenario B-leakage problem in pipelines system without NF models' supervision and Scenario C-leakage problem in pipelines system with NF models' supervision. Scenarios' results were all as expected and prove the supervision system ability to be an excellent communication tool for the oil transportation process. It can reduce the leakage lost, as the valve will close as soon as possible and reduce the repairing waiting time as the oil pipes will be empty.

This article presents the results of the first phase of the research. For future work, wireless communication control system for oil pipelines transmission grid will be developed. The sensors on the oil pipelines will send the data using wireless communication technique.

\section{REFERENCES}

[1] "Oil and environment", Eccos, 2016. [Online]. Available: http://www.eccos.us/al-gore-global-warming. [Accessed: 18- Jun- 2017].

[2] C. Carter. (2015 Nov). Brent Crude Oil performance 2016. [Online]. Available: http://moneyweek.com/prices-newscharts/oil. [Accessed: 18- Jun- 2017].

[3] B. Titlow and M. Tinger, Protecting the Planet Environmental Champions from Conservation to climate change, Prometheus Books, 2016.

[4] W. Burroughs, Climate change. Cambridge: Cambridge University Press, 2011.

[5] R. J. Kopp. (2006, November 17) "Replacing Oil: Alternative Fuels and Technologies | Resources for the Future", Rff.org, p.15-18. 2016. [Online]. Available: http://www.rff.org/research/publications/replacing-oilalternative-fuels-and-technologies. [Accessed: 18- Jun2017].

[6] "Reliable and innovative solutions for the oil and gas industry," Oil \& Gas -Siemens, W3.siemens.com, 2016. [Online].

http://w3.siemens.com/markets/global/en/oilgas/Pages/oil-gas.aspx. [Accessed: 18- Jun- 2017].

[7] "Safety Monitoring: Advanced Gas, Flame, and Particle 
Detection Solutions", Emerson Process Management, UK September 2014. 2016. [Online]. Available: http://www2.emersonprocess.com/siteadmincenter/PM\%2 ORosemount\%20Analytical\%20Documents/FGD_BRO_S afety_Monitoring.pdf. [Accessed: 18- Jun- 2017].

[8] Y. Yu, CC. Wu, XK. Xing, YC. Shi, YP. Li and LL. Zuo, "Correcting rated pump performance improves heavy oil pipeline efficiency," Oil \& Gas Journal, China University of Petroleum, Beijing, Peoples R China, vol. 112, no.7, pp. 108, 2014.

[9] Je. Bernard. "Security Technology in the Oil and Gas Industry: Managing Risk and Enhancing Operational Efficiency" Oil \& Gas Network Magazine, Osprey Informatics, October 2014. 2016. [Online]. Available: http://www.ospreyinformatics.com/osprey-gives-expertinsight-security-technologies-october-2014-oil-gasnetwork-magazine/ [Accessed: 18- Jun- 2017].

[10] K. Ross and G. Vogler, "Iraqis Mending Own Pipelines," Oil \& Gas Journal, Tulsa, Oklahoma, U.S.A. Vol. 107, no.7, pp. 50-53, 2009.

[11] iDirect - Oil \& Gas", Idirect.net, 2016. [Online]. Available: http://www.idirect.net/Applications/Oil-andGas.aspx. [Accessed: 18- Jun- 2017].

[12] iDirect, "Connecting the Digital Oil Field White Paper" Idirect.net, 13865 Sunrise Valley Drive Herndon, VA 20171, USA 2016. [Online]. Available: http://file:///D:/Smart\%20Grid/New/Supporting\%20Douc ment/idirect\%20oil\%20gas.pdf. [Accessed: 18- Jun- 2017

[13] A. Parwal , G. Parwal, A. Sharma and M. Khan " Implementation of Fuzzy Technique Based on LabVIEW for Control Gas System Using USB 6009" International Journal of Control and Automation, Vol. 6, No. 3, June, 2013

[14] E. Rich, K. Knight and S. B. Nair, Artificial Intelligence, McGraw-Hill ,1st edition, 2008.

[15] N. Arora and J. Saini, "Estimation and Approximation Using Neuro-Fuzzy Systems", International Journal of Intelligent Systems and Applications (IJISA), vol.8, no.6, pp.9-18, 2016.

[16] J. Ghiasi-Freez, A. Hatampour, P. Parvasi, “Application of Optimized Neural Network Models for Prediction of Nuclear Magnetic Resonance Parameters in Carbonate Reservoir Rocks", International Journal of Intelligent Systems and Applications (IJISA), vol.7, no.6, pp.21-32, 2015

[17] A. K. Kori, A.K. Sharma and A.K.S. Bhadoriya, "Neuro Fuzzy System Based Condition Monitoring of Power Transformer," International Journal of Computer Science Issues (IJCSI), vol. 9, issue 2, no 1, March 2012.

[18] M. Egorovna and V. Nikolaevna, "Artificial intelligence in problems of leak definition from the oil pipeline," International Conference on Mechanical Engineering, Automation and Control Systems (MEACS), 2014.

[19] A. Mohamed, M. Hamdi and S. Tahar, "Using Computational Intelligence for the Safety Assessment of Oil and Gas Pipelines: A Survey," CHAPTER, Data Science and Big Data: An Environment of Computational Intelligence, vol. 24, pp 189-207.

[20] Matlab \& Simulink: Simcscap TM User's Guide, R201 5B, The Math Works, Inc., 3 Apple Hill Drive Natick, 20072015.

[21] S. N. Danilin, S. A. Shchanikov and A. I. Galushkin, "The research of memristor-based neural network components operation accuracy in control and communication systems," 2015 International Siberian Conference on Control and Communications (SIBCON), pp. 1-6, May 2015.
[22] A. Kusagur, S. F. Kodad and S. B V Ram, "Modeling, Design \& Simulation of an Adaptive Neuro-Fuzzy Inference System (ANFIS) for Speed Control of Induction Motor," International Journal of Computer Applications, Foundation of Computer Science, vol. 6, no. 12, pp. 2945, September 2010.

[23] "Piezo Motion and Positioning systems." Physik Instrumente (PI) UK: Piezo, Physikinstrumente.co.uk, 2016. [Online]. Available: http://www.physikinstrumente.co.uk/technologies/piezo/? gclid=CLjmxoObrssCFarpwgodd3QIOw. [Accessed: 18Jun- 2017]

[24] "Hydraulic Equipment Components Suppliers | Engineers Edge | www.engineersedge.com", Engineersedge.com, $2016 . \quad$ [Online]. Available: http://www.engineersedge.com/engineering/Products_Dir ectory/Fluid_Power_Equipment/Hydraulic_Equipment_C omponents/. [Accessed: 18- Jun- 2017]

[25] "Hydraulic Valves: Directional Control Valve, Pressure Control Valve, Flow Control Valve," Parker Distributor Hydraulics. Damen Technical Agencies (DTA), Dta.eu, $2016 . \quad$ [Online]. Available: http://dta.eu/hydraulics/hydraulic-valves. [Accessed: 18Jun- 2017]

[26] J. S. R. Jang and Chuen-Tsai Sun, "Neuro-fuzzy modeling and control," in Proceedings of the IEEE, vol. 83, no. 3, pp. 378-406, Mar 1995.

[27] L. Zadeh, "Fuzzy Logic and Softcomputing", Plenary Speaker, Proceedings of IEEE International Workshop on Neuro Fuzzy Control, Muroran, Japan, 1993.

[28] J. R. Jang, "ANFIS: Adaptive-network, based fuzzy inference system", IEEE transaction on Systems, Man and Cybernetics, 1993, vol. 23, no. 3, pp. 665-685.

[29] "Gaussian curve membership function - MATLAB gaussmf - $\quad$ MathWorks United Kingdom", Uk.mathworks.com, 2017. [Online]. Available: https://uk.mathworks.com/help/fuzzy/gaussmf.html. [Accessed: 18- Jun- 2017].

\section{Authors' Profiles}

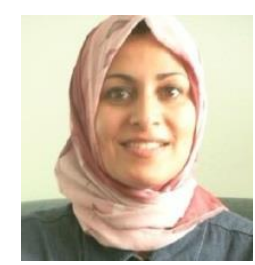

Dr Nagham H. Saeed is currently a lecturer at the University of West London. She received Bachelor degree in Computer \& Control, MSc in Mechtronics and $\mathrm{PhD}$ degree in I-MAN System. Dr. Saeed research interests are in optimization in communication networks.

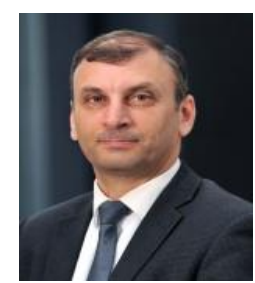

Dr Maysam F. Abbod received the Ph.D. degree in control engineering from The University of Sheffield, U.K., in 1992. He is currently a Reader of Electronic Systems with the Department of Electronic and Computer Engineering, Brunel University London, UK. He has authored over 50 papers in journals, nine chapters in edited books, and over 50 papers in refereed conferences. His current research interests include intelligent systems for modelling and optimization. He is a member of the IET (UK), and a Chartered Engineer (UK). He is serving as an Associate Editor of the Engineering Application of Artificial Intelligence (Elsevier). 
How to cite this paper: Nagham H. Saeed, Maysam.F. Abbod, "Modelling Oil Pipelines Grid: Neuro-fuzzy Supervision System", International Journal of Intelligent Systems and Applications(IJISA), Vol.9, No.10, pp.1-11, 2017. DOI: 10.5815/ijisa.2017.10.01 